\title{
EPOXY-GRAPHENE UV-CURED NANOCOMPOSITES
}

\author{
M. Martin-Gallego ${ }^{1}$, R. Verdejo ${ }^{1}$ M.A. Lopez-Manchado ${ }^{1}$, M. Sangermano ${ }^{2 *}$ \\ ${ }^{1}$ Instituto de Ciencia y Tecnología de Polímeros, CSIC, Juan de la Cierva, 3 28006-Madrid, \\ Spain. \\ ${ }^{2}$ Politecnico di Torino, Dipartimento di Scienza dei Materiali e Ingegneria Chimica, C.so \\ Duca degli Abruzzi 24, 10129, Torino.
}

\begin{abstract}
This work presents the preparation of functionalized graphene sheets (FGS)/epoxy coatings cured by cationic photopolymerization with enhanced mechanical properties. The kinetics of the photopolymerization process for formulations up to $1.5 \mathrm{wt} \%$ of graphene were evaluated by means of Real-Time FT-IR spectroscopy. The reinforcement of the cured coatings by the graphene was studied by measuring the dynamic mechanical properties and the surface hardness. An increase of almost $40{ }^{\circ} \mathrm{C}$ in the $T_{g}$ was obtained by adding $1.5 \mathrm{wt} \%$ of graphene to the epoxy matrix. A good dispersion state and interaction of the graphene with the matrix were observed by TEM and FE-SEM analyses.
\end{abstract}

Keywords: graphene, nanocomposites, photopolymerization

* Corresponding author: marco.sangermano@polito.it; Tel: +39 0110904651 


\section{INTRODUCTION}

Graphene is considered a two-dimensional carbon nanofiller with a one-atom-thick planar sheet of $\mathrm{sp}^{2}$ bonded carbon atoms that are densely packed in a honeycomb crystal lattice $[1,2]$. Graphene is predicted to have remarkable performance, such as high thermal conductivity, excellent electronic transport properties and superior mechanical properties [3-6]. In fact graphene sheets were demonstrated to have extraordinary electronic transport properties [7], combined with a wide set of other unusual properties [8]: their thermal conductivity and mechanical stiffness may rival the remarkable in-plane values for graphite $\left(3,000 \mathrm{Wm}^{-1} \mathrm{~K}^{-1}\right.$ and $1,060 \mathrm{GPa}$, respectively). Of particular interest is the fact that their fracture strength should be comparable to that of carbon nanotubes for similar types of defects [9-11]. Therefore, the tensile strength of graphene is similar or slightly higher than CNT, but much higher than steel and Kevlar.

The superior properties of graphene are also reflected in polymer/graphene nanocomposites, and it is evident that the transfer of such features to polymeric materials usable at the application level, holds a deep scientific interest. Novel graphene-based polymer composites are presently emerging as a new class of highly functional advanced materials that hold promise for a more versatile and cheaper alternative to carbon nanotubes-based composites. In fact, while the addition of carbon nanotubes to polymer matrices has already been shown to improve their mechanical, electrical and thermal properties [12], the challenge is now to exfoliate the graphite to single graphene sheets to be used as an inexpensive and feasible substitute to carbon nanotubes. These nanohybrid materials could show considerable improvement in properties that cannot normally be achieved using conventional composites or virgin polymers. 
In particular, polymer/graphene nanocomposites show superior, thermal, gas barrier, electrical, flame retardant and mechanical properties compared to the neat polymer [13-15]. It was reported that the improvement in mechanical and electrical properties of graphene based polymer nanocomposites are much better in comparison to that of other carbon filler-based polymer nanocomposites. In a previous paper [16] we have reported the use of graphene oxide to prepare graphene-acrylate nanocomposites by photopolymerization method. It was found that graphene sheets undergo excellent morphological distribution within the resin system, giving rise to transparent composites with unaltered thermal properties and enhanced electrically conductivity at loading ratios as low as $0.02 \% \mathrm{wt}$ of graphene oxide. The addition of graphene to polymeric matrix endowed excellent mechanical properties such as modulus and strength [17]. It was shown that at low nanofiller content graphene evidenced even better mechanical properties enhancement with respect to carbon nanotubes probably because of high specific area which could allow an important matrix-filler interaction [18].

Graphene and graphene-oxide sheets have been already added into epoxy-polymer matrices in order to enhanced thermal properties [19-21] of the cured materials. Also, mechanical properties of epoxy matrix were deeply enhanced by graphene dispersion. The young modulus of the epoxy-graphene nanocomposites was about $31 \%$ greater than the pristine epoxy matrix. The tensile strength of the baseline epoxy was enhanced by around $40 \%$ with graphene platelets. The fracture toughness of the nanocomposites showed around 53\% increase over epoxy [22].

Both the improvement of the mechanical properties in epoxies and the advantages of UVcuring make such systems interesting for scientific and industrial applications. In fact the UVpolymerization of multifunctional monomers is one of the most efficient methods available to generate three-dimensional polymeric networks [23]. Among the advantages of this 
technology the high cure speed, the reduced energy consumption, and absence of VOC emissions are the most remarkable. It is well known that the UV curing can be performed either by a radical or a cationic mechanism. The cationic photoinduced process presents some advantages compared to the radical one [24], in particular lack of inhibition by oxygen, lower shrinkage, good mechanical properties of the UV cured materials, and good adhesion properties to various substrates.

Despite the promising applications of graphene in epoxy UV-curable resins, to the best of our knowledge no reports are present in literature so far. Therefore, this paper intend to investigate the effect of graphene on the UV-curing process of an epoxy resin by evaluating the photopolymerization kinetics in real-time and the final thermal and viscoelastic properties of the cured materials.

\section{EXPERIMENTAL}

\subsection{Materials}

Bis-cycloaliphatic diepoxy resin 3,4-epoxycyclohexylmethyl-3',4'-epoxycyclohexyl carboxylate, (CE), triphenylsulfonium hexafluoroantimonate $\left(\mathrm{Ph}_{3} \mathrm{~S}^{+} \mathrm{SbF}_{6}{ }^{-}\right)$were purchased from Sigma-Aldrich (Milan, Italy) and used as received without any further purification. Functionalized graphene sheets (FGS) were synthesized as previously reported [25].

\subsection{Sample preparation}

Graphene was directly dispersed in the range between 0.5 to $1.5 \mathrm{wt} \%$ in the epoxy resin by means of Ultraturrax, a mixing procedure at $30000 \mathrm{rpm}$ for 10 minutes and 10 minutes in an ultrasonic bath was carried out to reach a good dispersion of the carbon filler in the resin. After mixing, $2 \mathrm{wt} \%$ photo-initiator (triphenylsulfonium hexafluoroantimonate) was added to 
each formulation. To prepare the DMTA and surface hardness test samples, the formulations were coated on glass substrates and cured with UV-light. The UV-induced polymerization was promoted by UV irradiation (UV lamp Italyquartz, Milano, Italy), with a light intensity on the surface of the sample of about $55 \mathrm{~mW} / \mathrm{cm}^{2}$ during 15 minutes $(7.5$ minutes each side of the sample) while 3 minutes were applied to the transparent pristine epoxy resin. Homogeneously UV-cured films of about $150 \mu \mathrm{m}$ in thickness and $25 \mathrm{~mm}$ in length were produced.

\subsection{Sample characterization}

The extent of the photo-polymerization reaction was determined by Real-Time-FTIR spectroscopy (using the instrument Thermo-Nicolet 5700). $25 \mu \mathrm{m}$-thick formulations were coated onto silicon wafers and simultaneously exposed to the UV beam (HAMAMATSU LC8) with an intensity of $35 \mathrm{~mW} / \mathrm{cm}^{2}$, to induce polymerization, and to the IR beam, to make an in-situ evaluation of the extent of reaction. Epoxy groups conversion was followed by monitoring the decrease in the absorbance of the epoxy groups centered at $750 \mathrm{~cm}^{-1}$ and normalized with the carbonyl peak centred at around $1700 \mathrm{~cm}^{-1}$. The conversion of the cured samples used for the thermal and viscoelastic characterization was determined by carrying out a single spectrum after 5 minutes of irradiation with the UV lamp at a light intensity of 55 $\mathrm{mW} / \mathrm{cm}^{2}$ on a coated film of about $25 \mu \mathrm{m}$.

The gel content was determined on the cured films by measuring the weight loss after $24 \mathrm{~h}$ extraction with chloroform at room temperature, according to the standard test method ASTM D2765-84.

The morphological characterizations of the cured films were performed by Scanning Field Emission Scanning Electron Microscopy (FESEM, Zeiss Supra 40) at $350 \mathrm{kV}$. All the 
samples were cryo-fractured in liquid nitrogen and the fracture surface was sputter coated with gold/palladium ( $\mathrm{Au} / \mathrm{Pd} 80 / 20)$. The study of the dispersion of the graphene was also carried out using transmission electron microscopy (TEM Leo 910 microscope at an acceleration voltage of $80 \mathrm{kV}$ ). Ultra-thin sections of the samples were prepared by cryoultramicrotomy at $-140{ }^{\circ} \mathrm{C}$ (Leica EM UC6).

Dynamic-mechanical thermal analysis (DMTA) was performed on a MK III Rheometrics Scientific Instrument at $1 \mathrm{~Hz}$ frequency in the tensile configuration. The storage modulus, $E$ ', and the loss factor, $\tan \delta$, were measured from $0{ }^{\circ} \mathrm{C}$ up to the temperature at which the rubbery state was attained. The $T_{g}$ value was assumed as the maximum of the loss factor curve $(\tan \delta)$.

DSC measurements were performed under nitrogen flux of $2 \mathrm{ml} / \mathrm{min}$, in the range of $25^{\circ} \mathrm{C}$ to $250{ }^{\circ} \mathrm{C}$ with a heating rate of $20{ }^{\circ} \mathrm{C} / \mathrm{min}$, with a Mettler TC $10 \mathrm{~A} / \mathrm{TC} 15 \mathrm{TA}$ controller instrument.

The pendulum hardness (Persoz, ASTM D4366) was measured from the damping of the oscillation of the pendulum. Pendulum hardness values are expressed in number of pendulum oscillations and are related directly to the softness of the surface of the sample. The shorter the damping time, the lower is the hardness.

The nanohardness of the coatings was measured by depth-sensing Berkovich nanoindentation (Nano-Indentation Tester, CSM Instruments) on the surface of plain coated samples. The maximum load was fixed at $50 \mathrm{mN}$ (5 indentations per sample, loading/unloading rate of $40 \mathrm{mN} / \mathrm{min}$ ), corresponding to a maximum indentation depth $\leq 10 \%$ of the thickness of each tested coating, so that the nano-hardness values are representative of the intrinsic properties of the film itself. 


\section{RESULTS AND DISCUSSION}

\subsection{UV-Curing process}

The aim of this study was the preparation and characterization of graphene/epoxy coatings cured by cationic photopolymerization processing. The effect of the graphene on the UVcuring process was evaluated by RT-FTIR analysis. Figure 1a shows representative FTIR spectra as a function of time for both pristine and $1.5 \mathrm{wt} \%$ FGS filled samples. The decrease of the epoxy group band, centered around $750 \mathrm{~cm}^{-1}$, as a function of irradiation time provides an indication of the extent of the reaction. Hence, the conversion curves of all samples were calculated from the normalized absorbance of the epoxy by the carbonyl band (Figure 1b). These conversion curves inform of the rate of polymerization, taken as the initial slope of the curves, and on the attained conversions, taken as the plateau values.

Figure la: FT-IR spectra in the region between 950-650 $\mathrm{cm}^{-1}$ for the neat epoxy and the formulation containing $1.5 \%$ FGS. Light intensity on the surface of the sample $35 \mathrm{~mW} / \mathrm{cm}^{2}$. Film thickness $25 \mu \mathrm{m}$.
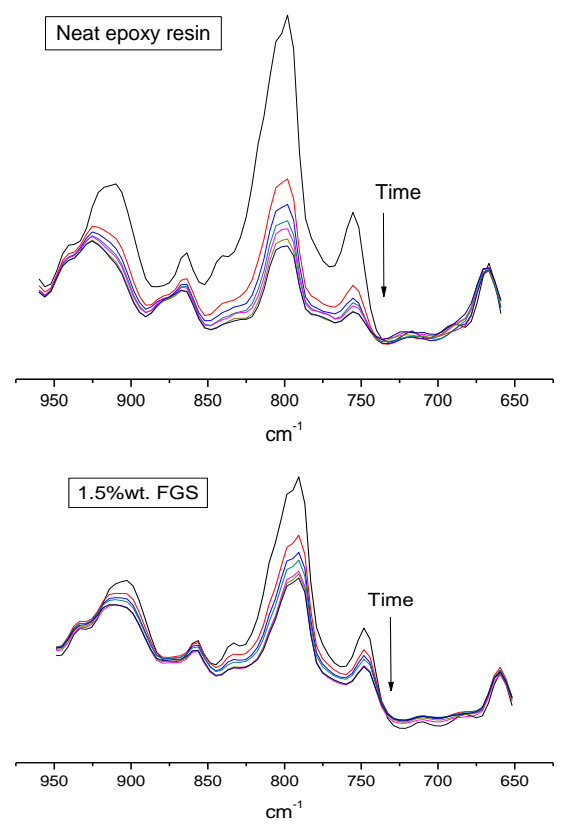
Figure 1b: Real-time FTIR conversion curves as a function of irradiation time for the pristine CE resin ( $\square$ ) and for the epoxy resin formulations containing 0.5 (०), 1 (४) and 1.5 ( $\nabla) w t \%$ of the graphene. Light intensity on the surface of the sample $35 \mathrm{~mW} / \mathrm{cm}^{2}$. Film thickness $25 \mu \mathrm{m}$.

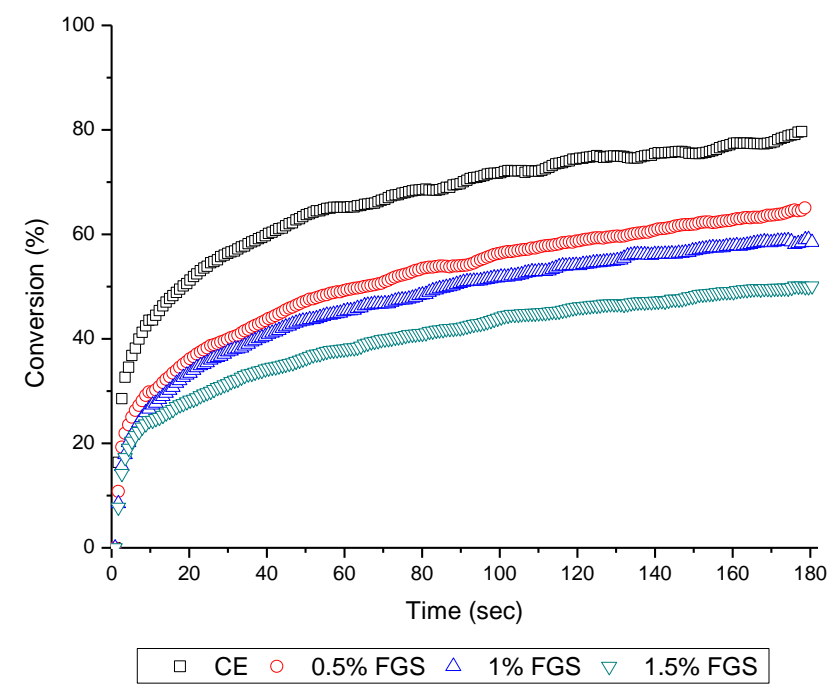

From the curves reported in Figure 1, it is evident the high reactivity of the epoxy groups of the $\mathrm{CE}$ resin with a quite high initial rate of polymerization. The epoxy group conversion levels off, after 3 minutes of irradiation, to a value of about $80 \%$. This is due to the formation of a glassy polymer network, which hindered the mobility of the reactive species so that a large number of unreacted epoxy groups remained trapped within the glassy polymer network. The addition of graphene to the photocurable formulations led to a decrease of both the polymerization rate and the final conversion as a function of loading fraction. The epoxy group conversion decreased to a minimum of $50 \%$ at 1.5 wt.- $\%$ FGS content. Meanwhile, the curing rates of filled samples were slightly lower than the unfilled system. The relatively lower rate of conversion may be due to the UV light shielding effect of graphene: a lower amount of reactive species is photogenerated resulting in a decrease of the epoxy group conversion. In fact, the efficiency of the photo-initiation process can be described by two quantum yields: the quantum yields of initiation, which represents the number of starting 
polymer chains per photons absorbed, and the quantum yields of polymerization, which is the number of monomer units polymerized per photons absorbed. Therefore, it is clear that the competition in absorption with the carbon filler implies a decrease of the photons absorbed by the photo-initiator. This can lead to a decrease of quantum yields and therefore to a lower epoxy group conversion. A similar behavior was previously observed when CNTs were dispersed into UV-curable epoxy resin [26].

In order to overcome this shielding effect, the formulations were cured for 5 minutes at 55 $\mathrm{mW} / \mathrm{cm}^{2}$. By increasing irradiation time and light intensity we could achieve fully cured networks. In Figure 2 the FT-IR spectra, in the region between $950-650 \mathrm{~cm}^{-1}$, are reported for the epoxy formulation containing $0.5 \%$ of FGS before and after 5 minutes of UV irradiation. It is possible to observe the almost complete disappearance of the epoxy group band centered at around $750 \mathrm{~cm}^{-1}$. All the cured samples showed a high gel content value (above 99\%, see Table 1), showing the absence of any extractable oligomer or unreacted monomer.

Figure 2: IR spectra of the formulation containing 0.5\% FGS before a) and after 5 minutes of UV irradiation b). Film thickness $25 \mu \mathrm{m}$.

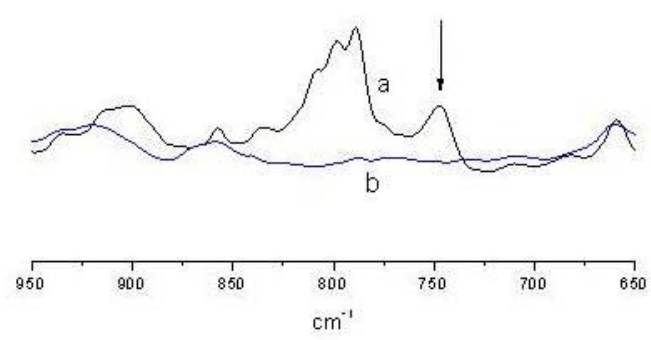

\subsection{Morphological investigation}

The morphology of the UV-cured hybrid materials was investigated by FESEM observations on the cross-sections of the films. In Figure 3 high magnification FESEM micrographs are reported for the cured epoxy resin and for the formulation containing $1.5 \mathrm{wt} \%$ of graphene. 
Figure 3a show a typical fragile behaviour of epoxy matrices, whereas a less brittle-like fracture is observed for the nanocomposite sample in figure $3 \mathrm{~b}$.

Figure 3: FE-SEM images obtained on the fracture surface of the cured samples. Pristine epoxy resin a) and nanocomposite film containing $1.5 \mathrm{wt} \%$ of graphene filler $b$ ).
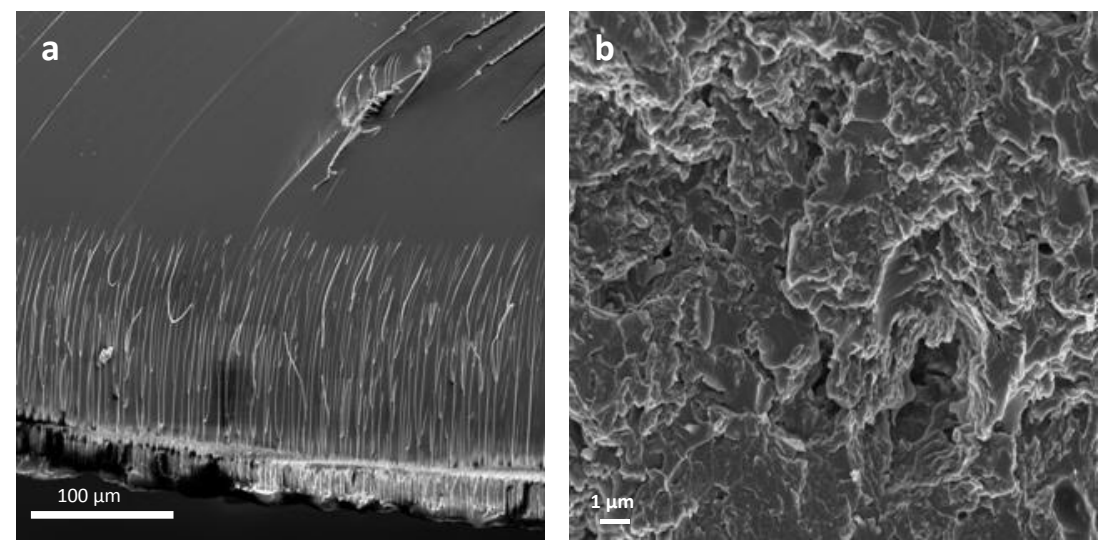

TEM images of the CE/graphene composites (Figure 4) show that single graphenes or stacks of graphene with thicknesses of several nanometers were uniformly dispersed throughout the polymer matrix. The particles appear to be completely embedded in the epoxy resin indicating an intercalated structure. This reflects a good compatibility between the graphene and epoxy resin without additional surface treatment.

Figure 4. TEM images of graphene-epoxy resin composite at a $1.5 \mathrm{wt} \%$ of filler.
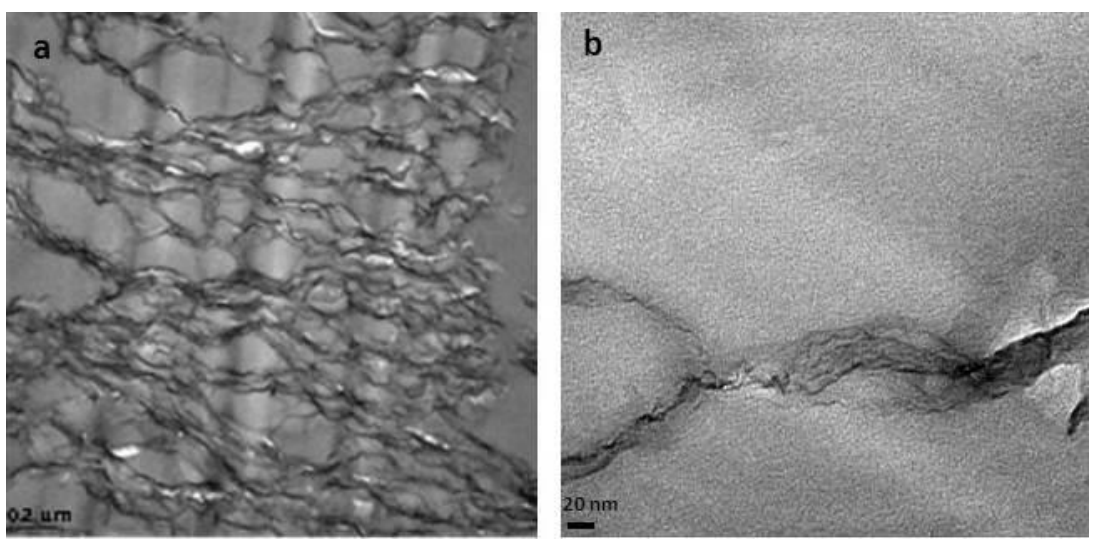


\subsection{Thermal and Viscoelastic characterization}

Thermal and dynamic-mechanical analysis were performed on the cured films. While DSC analysis gives information about the thermal behaviour, DMTA analysis allows the evaluation for the elastic and viscous components of the modulus of the material over a large temperature range. Therefore, these techniques give a complete characterization of the thermal and viscoelastic properties of the material. Firstly, the $T_{g}$ values of UV-cured films were evaluated by means of DSC analysis. It was possible to observe a strong increase of the $T_{g}$ value as a function of the graphene content in the UV-curable formulations (see Table 1). The $T_{g}$ increase could be due to the constraint effect of graphene sheets on the polymer chain mobility. These results suggest a uniform and homogeneous distribution of the graphene platelets within the polymeric network. In order to analyze this behavior, a further detailed study about the effect of graphene on the molecular dynamic of epoxy resin by dielectric spectroscopy will be carried out.

Table 1: Properties of UV-cured epoxy films obtained in the presence of graphene filler.

\begin{tabular}{|cccccc|}
\hline Sample & $\begin{array}{c}\text { Conv. } \\
{[\%]^{\mathbf{1}}}\end{array}$ & $\begin{array}{c}\text { Conv. } \\
{[\%]^{2}}\end{array}$ & $\begin{array}{c}\text { Gel content } \\
{[\%]^{3}}\end{array}$ & $\begin{array}{c}\boldsymbol{T}_{\boldsymbol{g}} \\
{\left[{ }^{\circ} \mathbf{C}\right]^{\mathbf{4}}}\end{array}$ & $\begin{array}{c}\boldsymbol{T}_{\boldsymbol{g}} \\
{\left[{ }^{\circ} \mathbf{C}\right]^{\mathbf{5}}}\end{array}$ \\
\hline CE & 80 & 100 & 100 & 155 & 206 \\
\hline $\mathbf{0 , 5 \%}$ FGS & 65 & 100 & 100 & 167 & 214 \\
\hline $\mathbf{1 \%}$ FGS & 59 & 95 & 100 & 181 & 230 \\
\hline $\mathbf{1 , 5 \%}$ FGS & 50 & 98 & 99 & 195 & 243 \\
\hline
\end{tabular}

1: plateau values of the RT-FTIR conversion curves as a function of irradiation time (UV intensity of $35 \mathrm{~mW} / \mathrm{cm}^{2}$ )

2: determined by the single spectra taken before and after $5 \mathrm{~min}$ of UV irradiation (UV intensity of $55 \mathrm{~mW} / \mathrm{cm}^{2}$ )

3: determined gravimetrically ASTM D2765-84

4: determined by DSC analysis, scan-rate $20{ }^{\circ} \mathrm{C} / \mathrm{min}$

5: determined by DMTA analysis, tensile configuration, $1 \mathrm{~Hz}$ frequency 
Viscoelastic characterization of the cured films was evaluated by DMTA analysis. CE resin shows a main relaxation process $\alpha$ assigned to the glass transition temperature (see Figure 5). This relaxation is gradually shifted towards higher temperatures with increasing graphene content in the composite. The $T_{g}$ values taken as the maximum of the $\tan \delta$ curves display the same upward trend than those previously determined by DSC (Table 1). It can be observed, anyway, that the $T_{g}$ values obtained by DMTA are higher than those obtained by DSC; this is a general behavior previously observed and it was attributed to a frequency effect. [27]

Plots of the storage modulus versus temperature (Figure 6) allow a direct comparison of the different UV cured networks. Graphene addition to the epoxy UV-curable system induces an increase of the storage modulus and, more important, of the viscoelastic properties by extending the performance of the elastic modulus to higher temperatures. The viscoelastic transition, seen as the decrease of the modulus, is shifted to higher temperature by increasing the graphene content in the photocurable formulations. It has been already suggested that the observed mechanical reinforcement may be related to the graphene high specific surface area, the enhanced nanofiller-matrix adhesion/interlocking arising from their rough surface, as well as the two dimensional planar geometry of the graphene platelets [28]. This is a remarkable result, since it clearly highlights the important increase on mechanical performance achieved for the hybrid films probably due to the interaction between the polymeric chains and the graphene platelets, with a consequent increase on stiffness and $T_{g}$ values.

These features can be accompanied by an increase on surface hardness. Therefore we investigated the surface hardness of cured films by means of Persoz pendulum and nanoindentation measurements. Figure 7 shows the surface hardness values measured by the Persoz pendulum and nano-indentation tests as a function of filler content. Persoz pendulum 
shows a clear increase of the cycles with FGS content. This hardness increase can be related to the hindering effect of the polymer chain mobility induced by the graphene platelets dispersed within the polymeric matrix. This result was also observed by the nano-indentation tests, since they both follow the same trend. However, the results obtained by nanoindentation have large standard deviation errors that should be taken into consideration.

Figure 5: Tan $\delta$ curves obtained by DMTA analysis for epoxy UV cured system and its graphene composites.

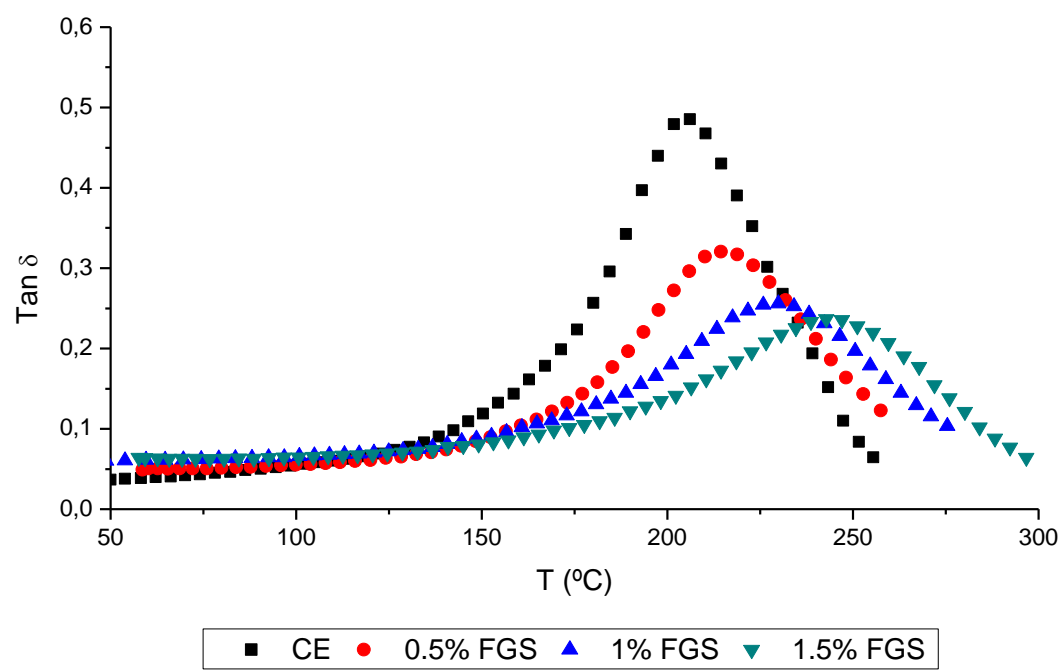


Figure 6: Storage modulus curves obtained by DMTA analysis for epoxy UV cured system and its graphene composites.

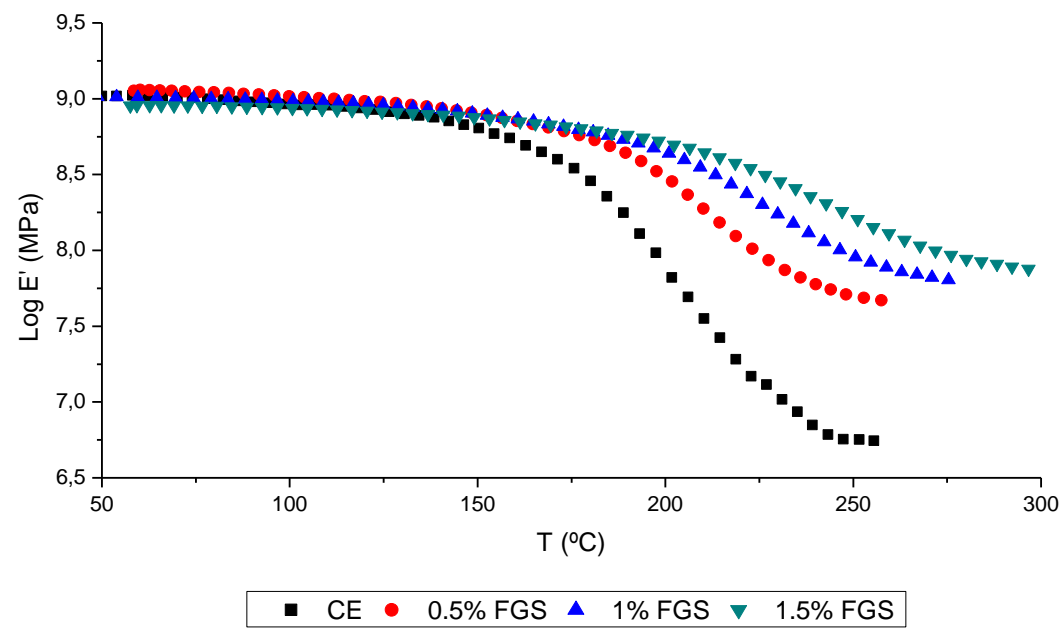

Figure 7: Number of oscillations of the Persoz pendulum and surface modulus (HIT) determined by nano-indentation test of cured films as a function of graphene content.

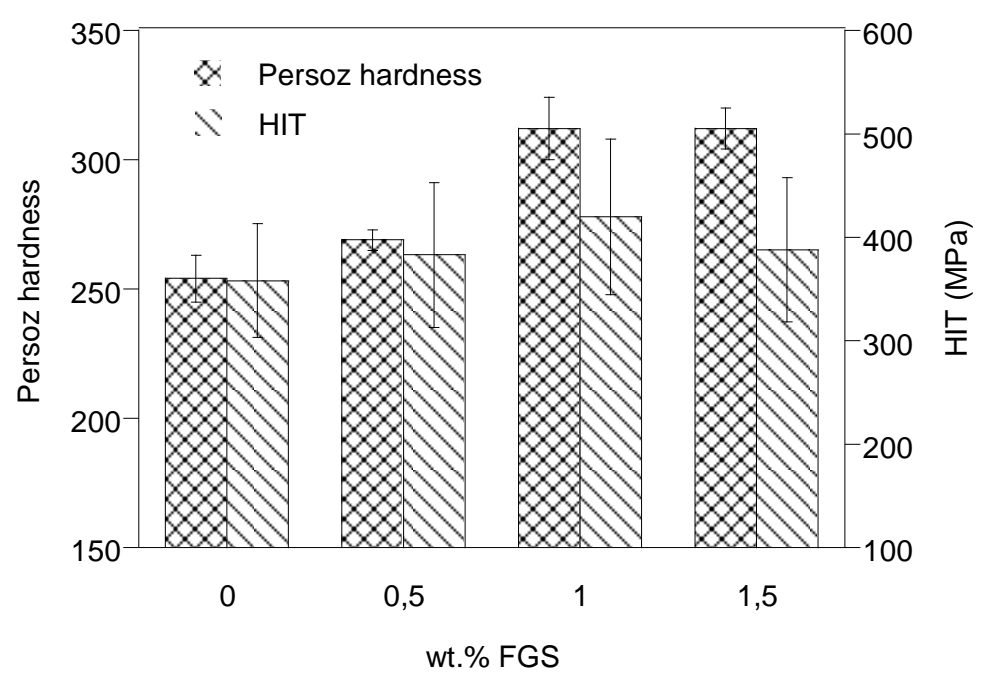

\section{CONCLUSIONS}

Graphene platelets were successfully dispersed in an epoxy resin and cured by UV-irradiation. The UV-shielding effect of the graphene filler induced a slight decrease on epoxy group 
conversion. Nevertheless, a fully crosslinked hybrid network was obtained, characterized by high gel content, high final conversion and good mechanical performance.

The addition of the graphene platelets induced an increase of stiffness of the cured epoxy network with an important increase on $T_{g}$ values and an evident enhanced performance of elastic modulus for higher temperature. The increase of stiffness of cured films induced an evident increase on surface hardness.

These results highlight the possibility to achieve advanced UV-cured epoxy films with outstanding mechanical behaviour.

\section{Acknowledgments}

The work was supported by the Spanish Ministry of Science and Innovation (MICINN) under project MAT 2010-18749. MMG thanks the CSIC for a JAE-Pre grant.

\section{REFERENCES}

[1] Novoselov KS, Geim AK, Morozov SV, Jiang D, Zhang Y, Dubonos SV, Grigorieva IV, Firsov AA. Science 2004;306:666-669.

[2] Novoselov KS, Geim AK, Morozov SV, Jiang D, Katsnelson MI., Grigorieva IV, Dubonos SV, Firsov AA. Nature 2005;438:197-200.

[3] Wang G, Yang J, Park J, Gou X, Wang B, Liu H, Yano J. J. Phys. Chem. C 2008;112:8192-8195.

[4] Wang G, Shen X, Wang B, Yao J, Park J. Carbon 2009;47:1359-1364.

[5] Li X, Wang X, Zhang L, Lee S, Dai H. Science 2008;319:1229-1231. 
[6] Blake P, Brimicombe PD, Nair RR, Booth TJ, Jiang D, Schedin F, Ponomarenko LA, Morozov SV, Gleeson HF, Hill EW, Geim AK, Novoselov KS. Nano Lett. 2008;8:17041708.

[7] Berger C, Song Z, Li T, Li X, Ogbazghi AY, Feng R, Dai Z, Marchenkov AN, Conrad EH, First PN, de Heer WA. J. Phys. Chem. B 2004;108:19912-19916

[8] Stankovich S, Dikin DA, Dommett GHB, Kohlhaas KM, E. J. Zimney EJ, Stach EA, Piner RD, T. Nguyen ST, Ruoff RS. Nature 2006;442:282-286.

[9] Dresselhaus MS, Dresselhaus G, Adv. Phys. 2002;51:1-186.

[10] Hirata M, Gotou T, Horiuchi S, Fujiwara M, Ohba M. Carbon 2004;42:2929-2937.

[11] Yu MF, Lourie O, Moloni K, Kelly TF, Ruoff RS, Science 2000;287:637-640.

[12] Shafer MS, Sandler J, In: "Carbon nanotube/nanofiber polymer composites", S. Advani Ed., World Scientific, 2006, pp. 1-59.

[13] Eda G, Chhowalla M. Nano Lett. 2009;9:814-8.

[14] Liang J, Xu Y, Huang Y, Zhang L, Wang Y, Ma Y, Li F, Guo T, Chen Y. J. Phys. Chem. C 2009;113:9921-9927.

[15] Kim H, Macosko CW. Polymer 2009;50:3797-3809.

[16] Sangermano M, Marchi S, Valentini L, Bittolo Bon S, Fabbri P. Macromol. Mater. Eng. 2011;296:401-407.

[17] Verdejo R, Bernal MM, Romasanta LJ, Lopez-Manchado MA. J. Mat. Chem. 2011;21:3301-3310.

[18] Rafiee MA, Rafiee J, Srivastava I, Wang Z, Song H, Yu ZZ, Karatkar N. Small 2011;6:179-183.

[19] Yu A, Ramesh P, Sun X, Bekyarova E, Itkis ME, Haddon RC. Adv. Mater. 2008;20:4740-4744. 
[20] Ganguli S, Roy AK, Anderson DP. Carbon 2008;46:806-817.

[21] Wang S, Tambraparni M, Qiu J, Tipton J, Dean D. Macromolecules 2009;42:5251-5255.

[22] Rafiee MA, Rafiee J, Wang Z, Song H, Yu ZZ, Koratkar N. ACS Nano 2009;3:38843890.

[23] Fouassier JP, Rabek JF. Radiation Curing in Polymer Science and Technology, Vol. I-IV, Elsevier, London, 1993.

[24] Sangermano M, Bongiovanni R, Malucelli G, Priola A. "New developments in cationic photopolymerization: process and properties" in "Horizons in Polymer Research", Bregg RK. Ed., Nova Science Publisher Inc., New York, 2006, pp. 61-82

[25] Verdejo R, Barroso-Bujans F, Rodriguez-Perez MA, de Saja JA, Lopez-Manchado MA. J. Mater. Chem. 2008;18:2221-2226

[26] Sangermano M, Pegel S, Potschke P, Voit B. Macromol. Rapid Commun. 2008;29:396400.

[27] Nielsen LE, “Mechanical Properties of Polymers and Composites”, New York, Dekker, 1994.

[28] Rafiee MA, Rafiee J, Yu ZZ, Koratkar N. Appl. Phys. Lett. 2009;95:223103 